ARTICLE

\title{
Materializing efficient methanol oxidation via electron delocalization in nickel hydroxide nanoribbon
}

Xiaopeng Wang ${ }^{1}$, Shibo $\mathrm{Xi}^{2,11}$, Wee Siang Vincent Lee (iD ${ }^{1,11}$, Pengru Huang ${ }^{1,3}$, Peng Cui ${ }^{4}$, Lei Zhao (iD ${ }^{5}$,

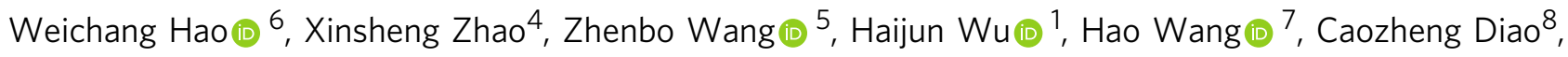
Armando Borgna ${ }^{2}$, Yonghua Du (1) ${ }^{9 凶}$, Zhi Gen Yu (i) ${ }^{10 凶}$, Stephen Pennycook ${ }^{1 凶}$ \& Junmin Xue (i) ${ }^{1 凶}$

Achieving a functional and durable non-platinum group metal-based methanol oxidation catalyst is critical for a cost-effective direct methanol fuel cell. While $\mathrm{Ni}(\mathrm{OH})_{2}$ has been widely studied as methanol oxidation catalyst, the initial process of oxidizing $\mathrm{Ni}(\mathrm{OH})_{2}$ to $\mathrm{NiOOH}$ requires a high potential of $1.35 \mathrm{~V}$ vs. RHE. Such potential would be impractical since the theoretical potential of the cathodic oxygen reduction reaction is at $1.23 \mathrm{~V}$. Here we show that a four-coordinated nickel atom is able to form charge-transfer orbitals through delocalization of electrons near the Fermi energy level. As such, our previously reported periodically arranged four-six-coordinated nickel hydroxide nanoribbon structure ( $\left.\mathrm{NR}-\mathrm{Ni}(\mathrm{OH})_{2}\right)$ is able to show remarkable methanol oxidation activity with an onset potential of $0.55 \mathrm{~V}$ vs. RHE and suggests the operability in direct methanol fuel cell configuration. Thus, this strategy offers a gateway towards the development of high performance and durable non-platinum direct methanol fuel cell.

\footnotetext{
${ }^{1}$ Department of Materials Science and Engineering, National University of Singapore, Singapore 117575, Singapore. ${ }^{2}$ Institute of Chemical and Engineering Sciences, Agency for Science, Technology and Research, Singapore 627833, Singapore. ${ }^{3}$ Guangxi Collaborative Innovation Center of Structure and Property for New Energy, Guangxi Key Laboratory of Information Materials, School of Material Science and Engineering, Guilin University of Electronic Technology, Guilin 541000, China. ${ }^{4}$ School of Physics and Electronic Engineering, Jiangsu Normal University, Jiangsu Sheng 221100, China. ${ }^{5}$ School of Chemistry and Chemical Engineering, Harbin Institute of Technology, Heilongjiang Sheng 150006, China. ${ }^{6}$ School of Physics, Beihang University, Beijing 100191 , China. 7 Department of Mechanical Engineering, National University of Singapore, Singapore 117575, Singapore. ${ }^{8}$ Singapore Synchrotron Light Sources (SSLS), National University of Singapore, Singapore 117603, Singapore. ${ }^{9}$ National Synchrotron Light Source II, Brookhaven National Laboratory, Upton, NY 11973, USA. ${ }^{10}$ Institute of High Performance Computing, Agency for Science, Technology and Research, Singapore 138632, Singapore. ${ }^{11}$ These authors contributed

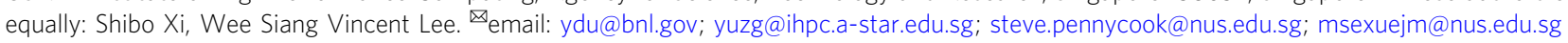


$\mathrm{M}$ ethanol is an extremely attractive fuel due to its high energy density and its ease of handling ${ }^{1-6}$. As a result, there is a concerted effort in the advancement in $\mathrm{CO}_{2}$ reduction efficiency to produce more methanol for energy storage, and to reduce the increasing $\mathrm{CO}_{2}$ pollutant generated in society ${ }^{7}$. With the increasing methanol availability, the challenge will be to develop an efficient device that can effectively convert methanol into electrical power. As such, direct-methanol fuel cells (DMFCs), being one such device that utilizes methanol as fuel, has attracted significant research interest due to its high portability and its promise of high energy density ${ }^{1-6,8-14}$. While DMFCs are poised as one of the future energy sources in a hypothesized carbon-neutral economy, there is still a huge deficit in the development of a suitable electrocatalyst which demands considerable research attention. The main underlying factor for this material selection deficit is in the anodic reaction of DMFCs where the methanol oxidation reaction (MOR) is kinetically sluggish due to its six-electron transfer process ${ }^{8-13}$. Thus, despite the significant effort devoted in the development of MOR catalysts in recent decades, platinum group metals (PGMs) remain the only known MOR catalysts that are reported to trigger methanol oxidation during DMFC operation ${ }^{8}$. This is largely due to the ability of PGMs to operate at $c a \cdot 0.4-0.6 \mathrm{~V}$ vs. RHE, which is below the theoretical oxygen reduction reaction (ORR) potential of $1.23 \mathrm{~V}$ vs. RHE. While PGMs have been used in DMFCs, their practicality as functional MOR catalyst is stifled by their high $\operatorname{cost}^{5,8,11}$. Hence, it is of significant importance to reduce the reliance in PGMs by developing an alternative material as a durable and cost-effective catalys

$\mathrm{Ni}(\mathrm{OH})_{2}$ has been widely studied as an electrocatalyst for various oxidation reactions which include MOR ${ }^{12,13}$. Before the MOR process, $\mathrm{Ni}(\mathrm{OH})_{2}$ has to be first electrochemically oxidized to $\mathrm{NiOOH}$ at a potential above $1.35 \mathrm{~V}$ vs. RHE in order to exhibit MOR activity ${ }^{12}$. Such potential would be impractical as a DMFC anode since it is higher than its cathodic ORR potential $(1.23 \mathrm{~V}$ vs. RHE). Thus, the need to oxidize $\mathrm{Ni}(\mathrm{OH})_{2}$ to $\mathrm{NiOOH}$ at high potential in order to trigger limited MOR activity in a threeelectrode electrochemical environment suggests that such material cannot be considered as functional MOR catalysts in DFMC configuration. This inadequacy of traditional $\mathrm{Ni}(\mathrm{OH})_{2}$ as a functional MOR catalyst is primarily due to the forbidden electron transfer on valence band near Fermi energy level in a traditional six-coordinated $\mathrm{Ni}$ atom, which ultimately leads to the ineffectiveness of $\mathrm{Ni}(\mathrm{OH})_{2}$ in oxidizing methanol. When $\mathrm{Ni}^{2+}$ is oxidized to $\mathrm{Ni}^{3+}$, an available charge-transfer orbital is formed which is then available for the electron transfer process during methanol oxidization to $\mathrm{CO}_{2}$. However, it is fundamentally challenging to create available charge-transfer orbitals near the Fermi energy level in traditional $\mathrm{Ni}(\mathrm{OH})_{2}$ due to these six-coordinated $\mathrm{Ni}$ atom without subjecting the material to impractical potential. Interestingly, it is unveiled in this work that when the coordination number of $\mathrm{Ni}$ is reduced to four, electrons can be delocalized near the Fermi energy level which ultimately generates an available charge-transfer orbital to facilitate the six-electron transfer process during MOR. Despite the importance of four-coordinated Ni atoms in the establishment of charge-transfer orbital due to delocalization, it is shown that this four-coordinated $\mathrm{Ni}$ atom must be paired to a neighboring six-coordinated $\mathrm{Ni}$ atom in order to achieve efficient methanol oxidation. As such, based on this insight, it is suggested that $\mathrm{Ni}(\mathrm{OH})_{2}$ with four/six coordinated $\mathrm{Ni}$ atoms would be highly suitable as a functional MOR catalyst.

Here we show that our previously reported strain-stabilized non-stochiometric $\mathrm{Ni}(\mathrm{OH})_{2}$ nanoribbon structure with alternating 4/6-coordinated $\mathrm{Ni}$ edge atoms $\left(\mathrm{NR}-\mathrm{Ni}(\mathrm{OH})_{2}\right)^{15}$ is a potential functional MOR catalyst. It is revealed that $\mathrm{NR}-\mathrm{Ni}(\mathrm{OH})_{2}$ is able to exhibit MOR activity in alkaline electrolyte at a significantly lower onset potential of $0.55 \mathrm{~V}$ vs. RHE, which is close to that of platinum anode. It is proven by both theoretical and experimental results that this highly efficient MOR activity is due to the alternating four-and six-coordinated $\mathrm{Ni}$ atoms. The operability of $\mathrm{NR}-\mathrm{Ni}(\mathrm{OH})_{2}$ is firstly assessed by determining the open circuit voltage (OCV) of the assembled DMFC. Unlike the DMFCs assembled with traditional $\mathrm{Ni}(\mathrm{OH})_{2}$ (negligible $\mathrm{OCV}$ ), the $\mathrm{NR}-\mathrm{Ni}$ $(\mathrm{OH})_{2}$ assembled DMFC is able to achieve a serviceable OCV of $0.58 \mathrm{~V}$, which is reasonably close to that of its counterparts assembled with traditional $\mathrm{Pt}(\mathrm{OCV}$ of $0.65 \mathrm{~V})$ and $\mathrm{PtRu}(\mathrm{OCV}$ of $0.70 \mathrm{~V})$. Our impressive result is, to the best of our knowledge, the first report of non-PGM MOR catalyst that can achieve an operable OCV in DFMC configuration. Furthermore, the initial assessment of $\mathrm{NR}-\mathrm{Ni}(\mathrm{OH})_{2}$ in DFMC configuration has shown that the device was able to achieve durable operation with zero $\mathrm{CO}$ poisoning. Thus, based on these positive indications of DFMC operability, it is expected that with more research, NR-Ni $(\mathrm{OH})_{2}$ can be further optimized to become an important nonPGM MOR catalyst in DFMC.

\section{Results}

MOR activity of $\mathrm{NR}-\mathrm{Ni}(\mathrm{OH})_{2}$. To properly trigger the operation of a DMFC, the anode potential is required to be smaller than the cathode potential (Supplementary Fig. 1a). Thus, the MOR catalyst must show the capacity to oxidize methanol into $\mathrm{CO}_{2}$ below theoretical ORR potential i.e., $1.23 \mathrm{~V}$ vs. a reversible hydrogen electrode (RHE). Here, the MOR activity of $\mathrm{NR}-\mathrm{Ni}(\mathrm{OH})_{2}$ is evaluated by conducting $\mathrm{CV}$ scans from 0 to $1.2 \mathrm{~V}$ in $1 \mathrm{M} \mathrm{KOH}+$ $1 \mathrm{M} \mathrm{CH}_{3} \mathrm{OH}$ electrolyte solution using a three-electrode system. Traditional Ni-based catalysts, including $\alpha / \beta-\mathrm{Ni}(\mathrm{OH})_{2}$, Ni metal, $\mathrm{NiFe}$, are used as controls (Supplementary Figs. 1b-e and 2). All potentials recorded are vs. RHE. To avoid the effect of Pt on MOR measurement, graphite paper was used as counter electrode. The sample after MOR measurement is further analyzed using inductively coupled plasma (ICP) chemical analysis whereby a low Pt content of $0.001 \%$ in the $\mathrm{NR}-\mathrm{Ni}(\mathrm{OH})_{2}$. Thus, based on this result, Pt effect on the MOR activity could be ignored. The MOR onset potential of the sample is as low as $0.55 \mathrm{~V}$, with two obvious oxidation peaks at $0.89 \mathrm{~V}$ (forward) and $0.79 \mathrm{~V}$ (backward), respectively (see Fig. 1a, in solid), while no oxidation peaks were seen in traditional Ni-based catalysts in potential range from 0 to $1.23 \mathrm{~V}$ (Supplementary Fig. 1b-e and 2). It is noted that the MOR oxidation peak $0.89 \mathrm{~V}$ is well below the theoretical ORR potential of $1.23 \mathrm{~V}$, indicating that $\mathrm{NR}-\mathrm{Ni}(\mathrm{OH})_{2}$ has promising application for a DMFC full cell. In contrast, no oxidation peaks are detected when the CV scan is conducted in $1 \mathrm{M} \mathrm{KOH}$ (dashed line, Fig. 1a). Thus, it can be safely concluded that the observed oxidation peaks arise from methanol oxidation. Furthermore, the sample shows excellent cycle stability, without obvious shift in oxidation peak position or decrease in current density after $3000 \mathrm{CV}$ cycles (Fig. 1b). As a comparison, the MOR activity of $\mathrm{Pt} / \mathrm{C}$ was also recorded under the same test condition (Fig. 1c), showing an onset potential of $0.54 \mathrm{~V}$ and two methanol oxidation peaks at $0.79 \mathrm{~V}$ (forward) and $0.74 \mathrm{~V}$ (backward), respectively, but with much lower peak current densities compared to that of $\mathrm{NR}-\mathrm{Ni}(\mathrm{OH})_{2}$. Moreover, the stability indicating the retained activity of electrocatalysts after long-term operation, was measured through chronoamperometric measurement using the previous method ${ }^{13}$. Over 3600 s operation $\mathrm{NR}-\mathrm{Ni}(\mathrm{OH})_{2}$ exhibits $16 \%$ in activity, while $\mathrm{Pt} / \mathrm{C}$ only has $4 \%$ activity, suggesting that $\mathrm{NR}-\mathrm{Ni}(\mathrm{OH})_{2}$ has better stability than Pt/C (Supplementary Fig. 3).

Next, open-circuit voltage (OCV) and stability measurements were used to identify the feasibility of $\mathrm{NR}-\mathrm{Ni}(\mathrm{OH})_{2}$ in DMFCs. The OCV measurement was conducted using the previous method $^{14}$, being benchmarked with $\alpha / \beta-\mathrm{Ni}(\mathrm{OH})_{2}, \mathrm{Ni}$ metal, NiFe 

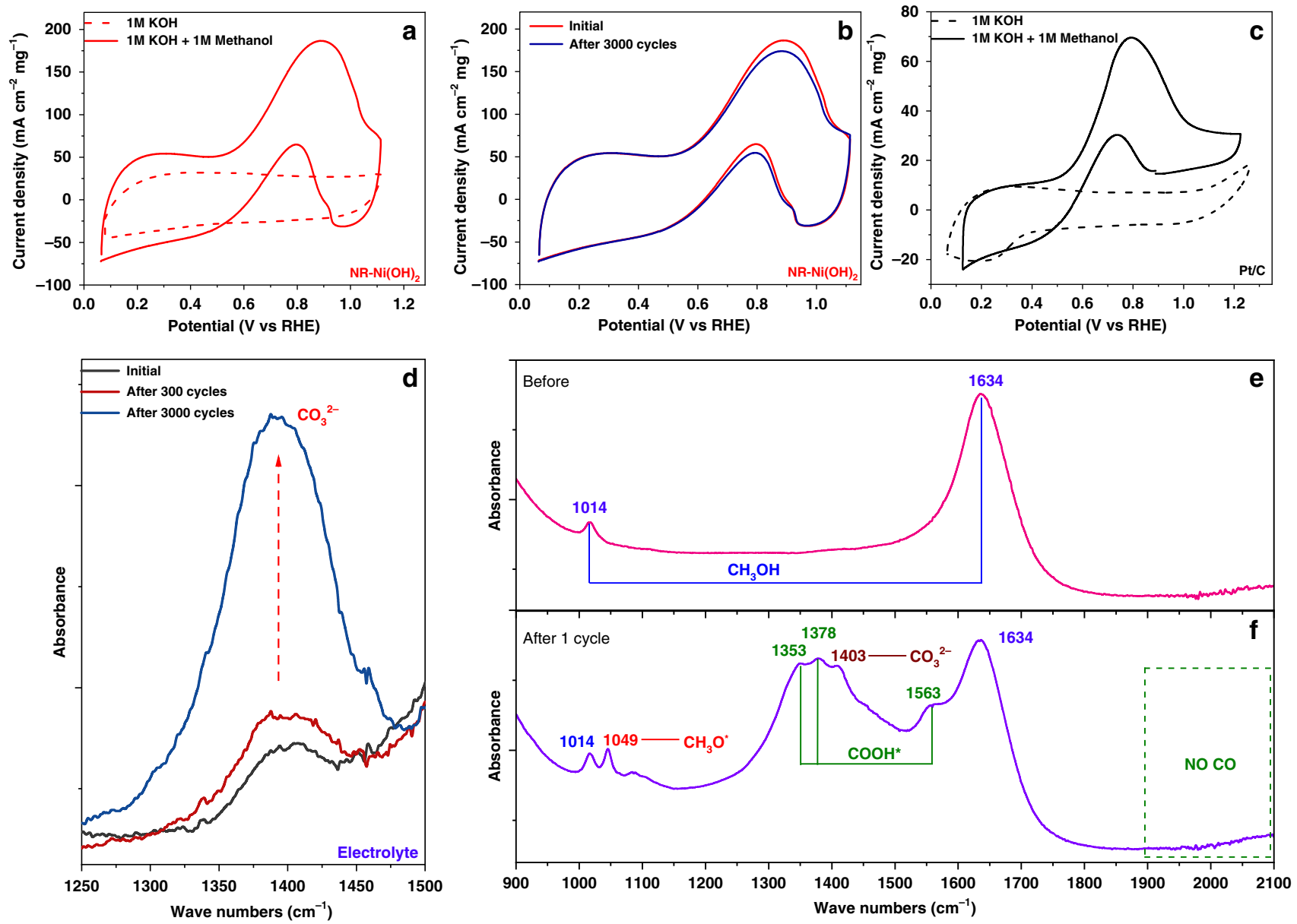

Fig. 1 Catalytic activity of $\mathbf{N R}-\mathbf{N i}(\mathbf{O H})_{2}$ in $\mathbf{1} \mathbf{M ~ K O H}+\mathbf{1} \mathbf{M} \mathbf{C H}_{\mathbf{3}} \mathbf{O H}$. a Cyclic voltammograms of NR-Ni(OH) 2 recorded in $1 \mathrm{M} \mathrm{KOH}$ (dashed) and $1 \mathrm{M} \mathrm{KOH}+$ $1 \mathrm{M} \mathrm{CH}_{3} \mathrm{OH}$ (solid) solutions at a scan rate of $20 \mathrm{mV} \mathrm{s}^{-1}$; $\mathbf{b}$ cycle stability of $\mathrm{NR}-\mathrm{Ni}(\mathrm{OH})_{2}$ recorded in $1 \mathrm{M} \mathrm{KOH}+1 \mathrm{M} \mathrm{CH} \mathrm{H}_{3} \mathrm{OH}$ solution after 3000 cycles; c cyclic voltammograms of $\mathrm{Pt} / \mathrm{C}$ recorded in $1 \mathrm{M} \mathrm{KOH}$ (dashed) and $1 \mathrm{M} \mathrm{KOH}+1 \mathrm{M} \mathrm{CH}_{3} \mathrm{OH}$ (solid) solutions at a scan rate of $20 \mathrm{mV} \mathrm{s}^{-1}$; $\mathbf{d}$ FTIR spectra of the electrolytes upon different CV cycles; e FTIR spectrum of electrode surface before CV scan; f FTIR spectrum of electrode surface after one CV cycle.

$\mathrm{LDH}$, standard $\mathrm{Pt} / \mathrm{C}$, and $\mathrm{PtRu} / \mathrm{C}$ catalyst. As shown in Supplementary Table 1 , nearly no electric output was seen for $\alpha / \beta-\mathrm{Ni}(\mathrm{OH})_{2}, \mathrm{Ni}$ metal and $\mathrm{NiFe} \mathrm{LDH}$ catalysts, while high $\mathrm{OCV}$ values $(\mathrm{OCV}>0.55 \mathrm{~V})$ were found in $\mathrm{NR}-\mathrm{Ni}(\mathrm{OH})_{2}, \mathrm{Pt} / \mathrm{C}$ and $\mathrm{PtRu} / \mathrm{C}$ catalysts. These results indicated, $\mathrm{NR}-\mathrm{Ni}(\mathrm{OH})_{2}$ could trigger the operation of DMFCs. A DMFC full cell prototype was further investigated with $\mathrm{NR}-\mathrm{Ni}(\mathrm{OH})_{2}$ and $\mathrm{Pt} / \mathrm{C}$ as the MOR and ORR catalysts, respectively, as shown in Supplementary Fig. 4. At a constant discharge current of $1.0 \mathrm{~mA} \mathrm{~cm}^{-2}$, the cell delivers a more stable output voltage, while the DMFC using $\mathrm{Pt} / \mathrm{C}$ as both anode and cathode shows an obvious decrease from $0.48 \mathrm{~V}$ to $0.33 \mathrm{~V}$, implying that $\mathrm{NR}-\mathrm{Ni}(\mathrm{OH})_{2}$ has better stability than $\mathrm{Pt} / \mathrm{C}$, which agrees with the electrochemical durability results (Supplementary Fig. 3). The slight decrease in output voltage of DMFC with the use of $\mathrm{NR}-\mathrm{Ni}(\mathrm{OH})_{2}$ may be due to the exchange of $\mathrm{OH}^{-}$ with carbonate $\left(\mathrm{CO}_{3}{ }^{2-}\right)$ and biocarbonate $\left(\mathrm{HCO}_{3}{ }^{-}\right)$, which can greatly decrease the conductivity of membrane ${ }^{16}$. All these results confirm that $\mathrm{NR}-\mathrm{Ni}(\mathrm{OH})_{2}$ is workable in a DMFC full cell.

Fourier transform infrared spectra (FTIR) is employed to identify the methanol oxidation process on $\mathrm{NR}-\mathrm{Ni}(\mathrm{OH})_{2}$. In the electrolyte solution, the concentration of $\mathrm{CO}_{3}{ }^{2-}$ continuously increased with increasing cycle number (Fig. 1d), indicating that methanol could be fully oxidized into $\mathrm{CO}_{2}{ }^{17}$. To identify the possible residual intermediates, the electrode surface after one CV cycle is characterized using FTIR, while the electrode surface without any $\mathrm{CV}$ scan is used as a control (Fig. 1e, f). Residual intermediates of $\mathrm{CH}_{3} \mathrm{O}^{*}$ and $\mathrm{COOH}^{*}$ were detected upon one $\mathrm{CV}$ scan (Detailed FTIR analysis is provided in Supplementary Fig. 5) ${ }^{17-20}$. The presence of $\mathrm{CH}_{3} \mathrm{O}^{*}$ and $\mathrm{COOH}^{*}$ as residual intermediates suggests that the reaction mechanism of MOR catalyzed by $\mathrm{NR}-\mathrm{Ni}(\mathrm{OH})_{2}$ is different from that of $\mathrm{Pt} / \mathrm{C}$, in which $\mathrm{CO}^{*}$ and $\mathrm{COOH}^{*}$ are usually the residual intermediates ${ }^{20}$.

MOR mechanism of NR-Ni(OH) $)_{2}$. In-situ FTIR was conducted to track the changes in the respective amounts of $\mathrm{CH}_{3} \mathrm{O}^{*}$ and $\mathrm{COOH}^{*}$ upon one $\mathrm{CV}$ cycle with an applied voltage from 0 to 1.2 $\mathrm{V}$, which are represented by the changes in band absorbance intensity (Fig. 2a, b). From 0 to $0.6 \mathrm{~V}$, the amount of $\mathrm{CH}_{3} \mathrm{O}^{*}$ is slightly decreased, indicating only little oxidation occurred but the major reaction has not yet started. Above $0.6 \mathrm{~V}$, the amount of $\mathrm{CH}_{3} \mathrm{O}^{*}$ dramatically increased, suggesting its fast accumulation and thus the start of the reaction, which agrees well with the onset potential of the forward oxidation peak shown in Fig. 1a. $\mathrm{COOH}$ is decreased in amount from 0 to $1.2 \mathrm{~V}$, but with a sudden increase in consumption rate above $0.6 \mathrm{~V}$, further confirming that the reaction starts above $0.6 \mathrm{~V}$. To gain an in-depth understanding of the methanol oxidation process on the nanoribbons, density functional theory was used to calculate the energy landscapes controlling the decomposition of intermediates. Based on the optimized layered unit cell of $\mathrm{Ni}(\mathrm{OH})_{2}$ and the experimental results, we constructed a $\mathrm{Ni}(\mathrm{OH})_{2}$ nanoribbon supercell (Supplementary Fig. 6). Ni atoms 

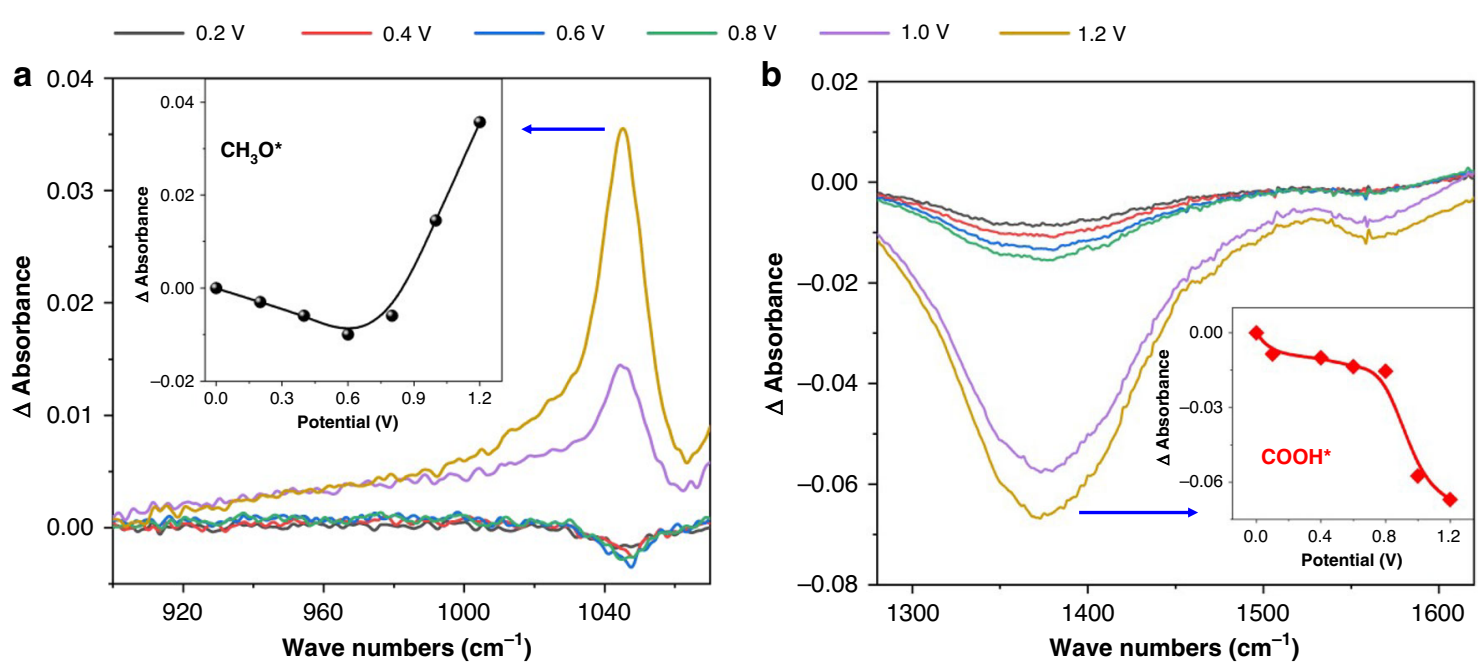

C

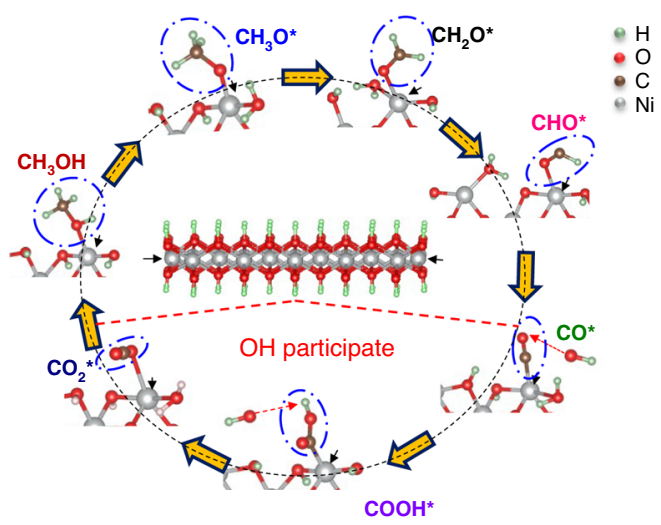

d

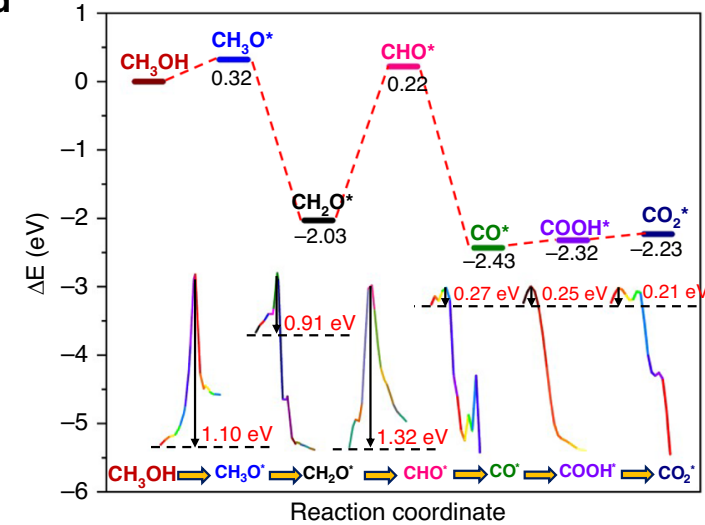

Fig. 2 MOR mechanism of NR-Ni(OH) $)_{2}$ a In-situ FTIR spectra of NR-Ni(OH) $2 /$ solution in the wave number ranges from 900 to $1070 \mathrm{~cm}^{-1}$ (inset representing the detailed variations of $\mathrm{CH}_{3} \mathrm{O}^{*}$ with potential); $\mathbf{b}$ In-situ FTIR spectra of NR-Ni(OH) /solution in the wave number ranges from 1280 to $1620 \mathrm{~cm}^{-1}$ (inset showing the detailed variations of $\mathrm{COOH}^{\star}$ with potential). $\mathbf{c}$ Schematic of the MOR mechanism for $\mathrm{NR}-\mathrm{Ni}(\mathrm{OH})_{2}$; $\mathbf{d}$ Calculated reaction free energy and energy barriers during MOR.

within the ribbon are fully saturated by six $\mathrm{OH}$, while the fourcoordinated $\mathrm{Ni}$ atoms at the edges are bonded to four $\mathrm{OH}$, leaving two dangling bonds. These unsaturated $\mathrm{Ni}$ atoms are thus able to provide the active sites for methanol adsorption. Furthermore, based on the simulation results, the methanol adsorption energy at the four-coordinated $\mathrm{Ni}$ atoms at the edges is much lower than at saturated $\mathrm{Ni}$ atoms within the ribbon (detailed analysis in Supplementary Fig. 7), which further suggests its thermodynamic feasibility. In the subsequent dehydrogenation steps, $\mathrm{O}-\mathrm{H}$ and $\mathrm{C}-\mathrm{H}$ chemical bonds are broken with the participation of an adjacent six-coordinated $\mathrm{Ni}$ atom, and the proton absorbs on the neighboring unsaturated $\mathrm{OH}$ (two-coordinated $\mathrm{OH}$, shared by four and six-coordinated $\mathrm{Ni}$ atoms, as the yellow arrow indicates in the supporting information) (Fig. 2c). In other words, the fourcoordinated $\mathrm{Ni}$ atom is responsible for efficient methanol adsorption, and the subsequent conversion of methanol to carbon dioxide is very efficiently achieved as those four-coordinated $\mathrm{Ni}$ atoms are located next to a six-coordinated $\mathrm{Ni}$ atom. Based on our calculated energy landscape, a MOR pathway of $\mathrm{CH}_{3} \mathrm{OH}^{*} \rightarrow$ $\mathrm{CH}_{3} \mathrm{O}^{*} \rightarrow \mathrm{CH}_{2} \mathrm{O}^{*} \rightarrow \mathrm{CHO}^{*} \rightarrow \mathrm{CO}^{*} \rightarrow \mathrm{COOH}^{*} \rightarrow \mathrm{CO}_{2}{ }^{*}$ is proposed (Fig. 2c, d). Details of the MOR activity calculations are provided in the Supplementary Discussions. Due to our periodically arranged four-six-coordinated $\mathrm{Ni}$ atoms, methanol absorption and its subsequent conversion to $\mathrm{CO}_{2}$ is highly efficient. This also explains why $\beta-\mathrm{Ni}(\mathrm{OH})_{2}$ and $\alpha-\mathrm{Ni}(\mathrm{OH})_{2}$ show negligible
MOR activity, while $\mathrm{NR}-\mathrm{Ni}(\mathrm{OH})_{2}$ exhibits remarkable MOR activity in the alkaline electrolyte (Supplementary Fig. 2).

It is worth noting that the dehydrogenation steps where the $\mathrm{O}-\mathrm{H} / \mathrm{C}-\mathrm{H}$ chemical bonds are broken, require relatively higher energy barriers than those needed in the subsequent steps (Fig. 2c). Thus, these steps are considered as the rate-determining steps, agreeing well with the in-situ FTIR results. It is also noted that there is a potential difference between the forward $(0.89 \mathrm{~V})$ and backward $(0.79 \mathrm{~V})$ oxidation peaks, which is due to the change in the rate-determining step from $\mathrm{O}-\mathrm{H}$ to $\mathrm{C}-\mathrm{H}$ bond breaking during the dehydrogenation process (Supplementary Fig. 8). More details of the change in the rate-determining step are given in Supplementary Discussions. Note that the $\mathrm{CO}^{*}$ oxidation step $\left(\mathrm{CO}^{*} \rightarrow \mathrm{COOH}^{*}\right)$ is immediate as it has a much lower energy barrier as compared to $\mathrm{CH}_{3} \mathrm{OH}$ dehydrogenations. This is in good agreement with the in-situ FTIR result, as there is no detectable $\mathrm{CO}$ attached on the electrode surface after applying a voltage from 0 to $1.2 \mathrm{~V}$ (Supplementary Fig. 9). Thus, based on these collective results, there is negligible $\mathrm{CO}$ poisoning for $\mathrm{NR}-\mathrm{Ni}(\mathrm{OH})_{2}$.

Charge-transfer orbitals formation through delocalization of electrons near the Fermi energy level. Previous research indicated that charge transfer in the electrocatalytic reaction for 

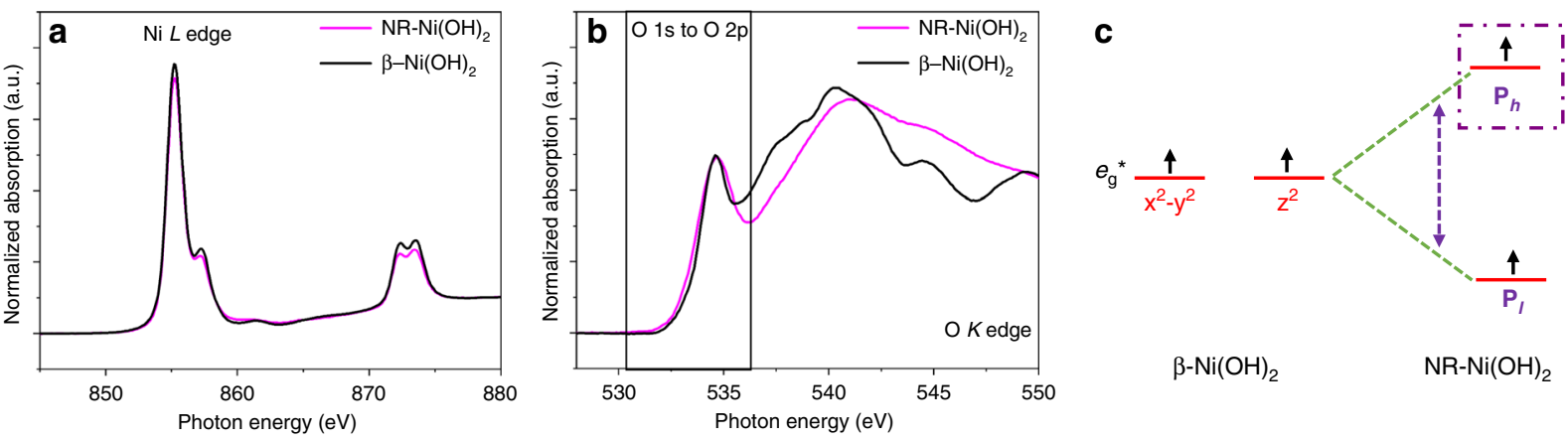

$\beta-\mathrm{Ni}(\mathrm{OH})_{2}$

$\mathrm{NR}-\mathrm{Ni}(\mathrm{OH})_{2}$
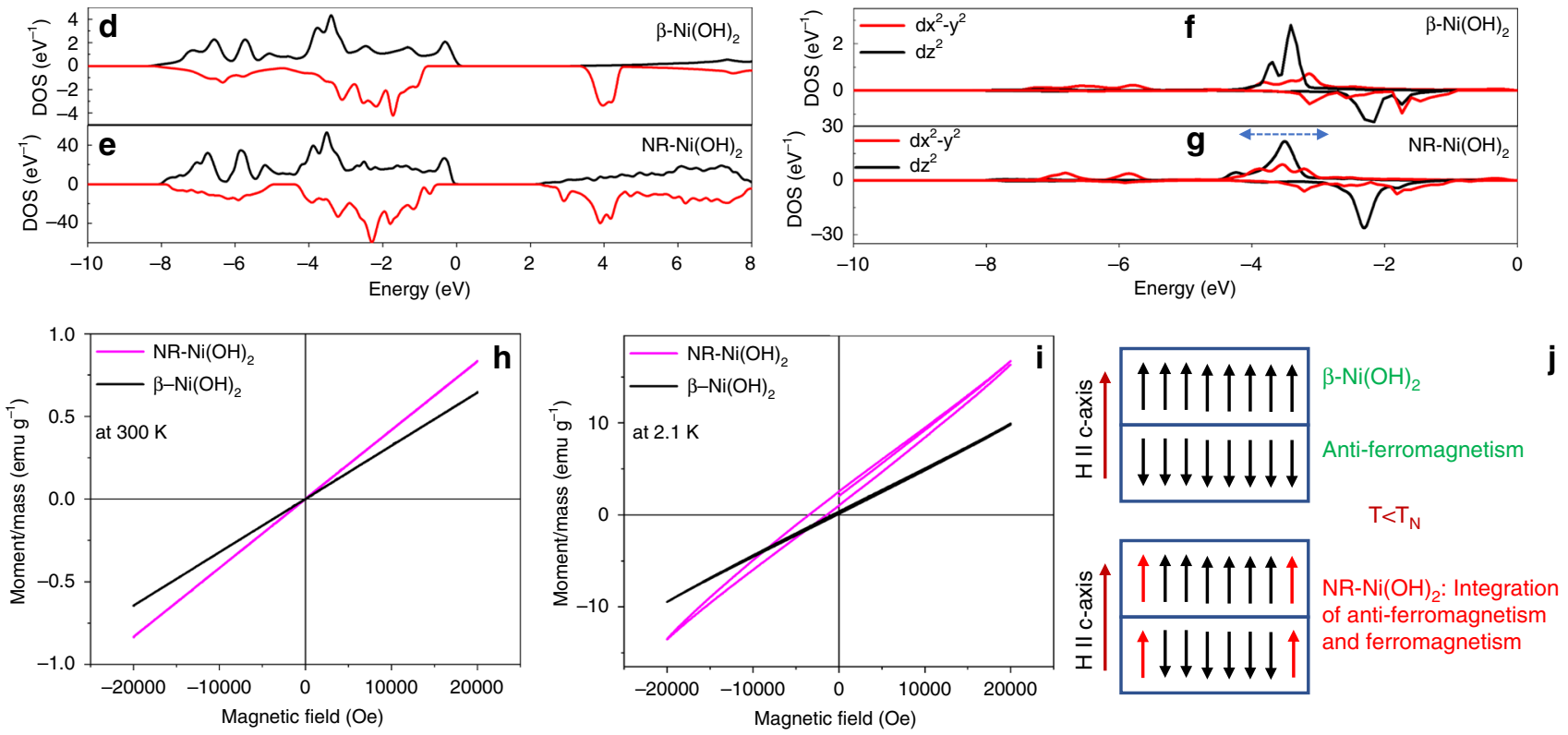

Fig. 3 Near-edge $\mathbf{X}$-ray absorption fine structure and magnetic measurement. a $\mathrm{Ni} L$ edge spectra of $\beta-\mathrm{Ni}(\mathrm{OH})_{2}$ and $\mathrm{NR}-\mathrm{Ni}(\mathrm{OH})_{2} ; \mathbf{b} \mathrm{O} K$ edge spectra of $\beta-\mathrm{Ni}(\mathrm{OH})_{2}$ and $\mathrm{NR}-\mathrm{Ni}(\mathrm{OH})_{2} ; \mathbf{c}$ schematic of $\mathrm{NR}-\mathrm{Ni}(\mathrm{OH})_{2}$ e $_{\mathrm{g}}{ }^{*}$ orbital splitting; $\mathbf{d}$, e projected density of states $(\mathrm{PDOS})$ of $\beta-\mathrm{Ni}(\mathrm{OH})_{2}$ and $\mathrm{NR}-\mathrm{Ni}(\mathrm{OH})_{2}$, respectively; $\mathbf{f}, \mathbf{g}$ PDOS of $e_{\mathrm{g}}{ }^{\star}$ orbitals for $\beta-\mathrm{Ni}(\mathrm{OH})_{2}$ and $\mathrm{NR}-\mathrm{Ni}(\mathrm{OH})_{2}$, respectively; $\mathbf{h} \mathrm{M}-\mathrm{H}$ loops of $\beta-\mathrm{Ni}(\mathrm{OH})_{2}$ and $\mathrm{NR}-\mathrm{Ni}(\mathrm{OH})_{2}$ at $300 \mathrm{~K} ; \mathbf{i} \mathrm{M}-\mathrm{H}$ loops of $\beta-\mathrm{Ni}(\mathrm{OH})_{2}$ and $\mathrm{NR}-\mathrm{Ni}(\mathrm{OH})_{2}$ at $2.1 \mathrm{~K} ; \mathbf{j}$ schematic of $\beta-\mathrm{Ni}(\mathrm{OH})_{2}$ and $\mathrm{NR}-\mathrm{Ni}(\mathrm{OH})_{2}$ magnetic properties.

transition metal hydroxide usually occurs on the filled lowerHubbard band (LHB) ${ }^{21,22}$. The detailed electronic orbitals of the traditional $\mathrm{Ni}(\mathrm{OH})_{2}$ are shown in Supplementary Fig. 10. To unveil the factors leading to the superior MOR activity exhibited by the alternating four-six-coordinated $\mathrm{NR}-\mathrm{Ni}(\mathrm{OH})_{2}$, the electronic structure is first examined using near-edge X-ray absorption fine structure (NEXAFS). For comparison, conventional $\beta-\mathrm{Ni}$ $(\mathrm{OH})_{2}$ is used as the benchmark sample. Figure $3 \mathrm{a}$, b shows the $\mathrm{Ni} L_{2,3}$ and $\mathrm{O} K$ edge X-ray absorption spectra. Ni $L$ edge data of $\mathrm{NR}-\mathrm{Ni}(\mathrm{OH})_{2}$ reveals a generally similar profile to that of $\beta-\mathrm{Ni}$ $(\mathrm{OH})_{2}$, which implies that both samples have very similar local chemical environment. This result suggests that all $\mathrm{Ni}$ atoms in $\mathrm{NR}-\mathrm{Ni}(\mathrm{OH})_{2}$ are arranged in $\mathrm{NiO}_{6}$ octahedron, which agrees well with our previous report ${ }^{15}$. However, some mismatch exists between $\mathrm{NR}-\mathrm{Ni}(\mathrm{OH})_{2}$ and $\beta-\mathrm{Ni}(\mathrm{OH})_{2}$ as all the peaks are broader for $\mathrm{NR}-\mathrm{Ni}(\mathrm{OH})_{2}$. In order to further understand the structural differences, $\mathrm{O} K$ edge $\mathrm{X}$-ray absorption is analyzed (Fig. $3 \mathrm{~b}$ ). The energy range between $530.5 \mathrm{eV}$ to $537.5 \mathrm{eV}$ corresponds to $\mathrm{O} 1 \mathrm{~s}$ to $\mathrm{O} 2 \mathrm{p}$ jump, which is mainly related to the electronic states of $e_{\mathrm{g}}{ }^{*}$. No pre-peaks are found in this energy range which shows that $\mathrm{NR}-\mathrm{Ni}(\mathrm{OH})_{2}$ is well-crystallized ${ }^{23}$. At the same time, the peak located at $534.0 \mathrm{eV}$ becomes broad which can suggest either there are more electronic states in the $e_{\mathrm{g}}{ }^{*}$ orbitals, or the splitting of $e_{\mathrm{g}}{ }^{*}$ orbitals has occurred. The schematic diagram of $e_{\mathrm{g}}{ }^{*}$ splitting is shown in Fig. 3c, with the higher energy orbital denoted as $P_{h}$ and the lower energy orbital denoted as $P_{l}$. The energy level splitting becomes more obvious with all the peaks becoming broader in energy range larger than $537.5 \mathrm{eV}(\mathrm{O}$ 1s to higher orbitals jump, e.g., O 3p).

The $e_{\mathrm{g}}{ }^{*}$ splitting can be further understood using density functional theory (DFT). Figure $3 \mathrm{~d}$, e show the PDOS of $\beta-\mathrm{Ni}$ $(\mathrm{OH})_{2}$ and $\mathrm{NR}-\mathrm{Ni}(\mathrm{OH})_{2}$, respectively. Above the Fermi level $(>0 \mathrm{eV})$, the black peak ( 3 to $7 \mathrm{eV}, a_{1 \mathrm{~g}}{ }^{*}$ orbital) of the NR-Ni $(\mathrm{OH})_{2}$ is red-shifted as compared with $\beta-\mathrm{Ni}(\mathrm{OH})_{2}$, and it overlaps with the red peaks $\left(2-5 \mathrm{eV}\right.$, unoccupied $e_{\mathrm{g}}{ }^{*}$ orbitals or upperHubbard band (UHB)). Since $a_{1 \mathrm{~g}}{ }^{*}$ is a delocalized orbital, its overlapping with the UHB results in the delocalization of the UHB. Furthermore, there is a splitting of peaks $(2-5 \mathrm{eV})$ for NR$\mathrm{Ni}(\mathrm{OH})_{2}$, which indicates the splitting of the UHB. This theoretical result agrees well with the NEXAS data (Fig. 3b). The isosurface charge density indicates that the UHB delocalization in $\mathrm{NR}-\mathrm{Ni}(\mathrm{OH})_{2}$ is resulted from the four-coordinated $\mathrm{Ni}$ atoms (Supplementary Fig. 11). The $e_{\mathrm{g}}{ }^{*} \mathrm{PDOS}$ of $\beta-\mathrm{Ni}(\mathrm{OH})_{2}$ and $\mathrm{NR}-\mathrm{Ni}(\mathrm{OH})_{2}$ are plotted to analyze the LHB electronic states shown in Fig. $3 \mathrm{f}, \mathrm{g}$. The result shows the broadening and splitting of $e_{\mathrm{g}}{ }^{*}$ orbitals in the energy range -8 to -4 and 2 to $6 \mathrm{eV}$. This indicates that the LHB of NR-Ni(OH $)_{2}$ has become delocalized. The $e_{\mathrm{g}}{ }^{*}$ PDOS of edge Ni atoms are plotted to analyze the LHB 
delocalization in NR-Ni(OH) $)_{2}$ (Fig. 3g). The results indicated that the broadening and splitting of $e_{\mathrm{g}}{ }^{*}$ orbitals resulted from the edge $\mathrm{Ni}$ atoms. The isosurface charge density is further calculated to analyze the LHB delocalization in NR-Ni(OH) ${ }_{2}$ (Supplementary Fig. 12 and Fig. 4c). There is an obvious shape deformation for edge $\mathrm{O}$ and $\mathrm{Ni}$ atoms in $\mathrm{NR}-\mathrm{Ni}(\mathrm{OH})_{2}$. At the same time, the orbitals of these edge atoms become larger as compared with those of interior atoms. These results clearly indicate that the unique electronic states of the four-coordinated $\mathrm{Ni}$ atoms are the reasons for LHB delocalization.

The electron delocalization of the $e_{\mathrm{g}}{ }^{*}$ orbitals is further analyzed using a superconducting quantum interface device (SQUID) magnetometer. The Neel temperature $\left(T_{\mathrm{N}}\right)$ is firstly identified through variations in the moment as a function of temperature for the ZFC (zero-field cooled) and FC (field cooled) cases with applied magnetic field $\mathrm{H}=100 \mathrm{Oe}$. As shown in in Supplementary Fig. 13, $T_{\mathrm{N}}$ for $\mathrm{NR}-\mathrm{Ni}(\mathrm{OH})_{2}$ and $\beta-\mathrm{Ni}(\mathrm{OH})_{2}$ are $21.95 \mathrm{~K}$ and $24.75 \mathrm{~K}$, respectively. Both $\mathrm{NR}-\mathrm{Ni}(\mathrm{OH})_{2}$ and $\beta-\mathrm{Ni}(\mathrm{OH})_{2}$ exhibit paramagnetic behavior when the temperature is above $T_{\mathrm{N}}$ (Fig. $3 \mathrm{~h}$ ). However, when the temperature is below $T_{\mathrm{N}}, \beta-\mathrm{Ni}(\mathrm{OH})_{2}$ shows anti-ferromagnetic behavior, while $\mathrm{NR}-\mathrm{Ni}(\mathrm{OH})_{2}$ shows an integration of both ferromagnetic and anti-ferromagnetic behavior (Fig. 3i). It is reported that the $\mathrm{Ni}^{2+}$ moments in (00l) planes are ferromagnetically ordered ${ }^{24}$. However, due to the strong interlayer bonding energy with the neighboring $(00 l), \mathrm{Ni}^{2+}$ moments are antiferromagnetically ordered along the $c$-axis ${ }^{24}$. This means that the electron spin direction on $\left(x^{2}-y^{2}\right)$ and $z^{2}$ orbitals $\left(e_{\mathrm{g}}{ }^{*}\right.$ energy band) in neighboring $(00 l)$ planes are inverse. The electronic orbitals of $\mathrm{Ni}(\mathrm{OH})_{2}$ are provided in Supplementary Fig. 10a. Thus, the remanence $\left(M_{\mathrm{r}}\right)$ depends on the number of uncompensated surface layers. For an even number of $(00 l)$ layers, the moments are compensated which leads to anti-ferromagnetic ordering (Fig. 3j). On the other hand, the uncompensated moments in an odd number of $(00 l)$ layers will yield $M_{\mathrm{r}}$ which ultimately leads to ferrimagnetic ordering. As a result, the traditional $\mathrm{Ni}(\mathrm{OH})_{2}$ can either exhibit anti-ferromagnetism or ferromagnetism, depending on the number of layers.

The low dose scanning transmission electron microscopy (STEM) indicates that more than $89 \%$ of $\mathrm{NR}-\mathrm{Ni}(\mathrm{OH})_{2}$ are double-layer in our previous work ${ }^{15}$. Based on the statistical orientation of $\mathrm{NR}-\mathrm{Ni}(\mathrm{OH})_{2}$, only $1 / 3$ will be oriented with $\mathrm{H} \|_{c}$ axis on average. As a result, only $3 \%$ of $\mathrm{NR}-\mathrm{Ni}(\mathrm{OH})_{2}$ (since these $3 \% \mathrm{NR}-\mathrm{Ni}(\mathrm{OH})_{2}$ consist of three layers and the two layers are compensated, which results in only $1 \%$ uncompensated layers contributing to the effect) would yield $M_{\mathrm{r}}$ leading to ferrimagnetic ordering. Due to the nearly negligible amount of uncompensated layers in the $\mathrm{NR}-\mathrm{Ni}(\mathrm{OH})_{2}$, their effect could be practically ignored. Based on the theory mentioned earlier, $\mathrm{NR}-\mathrm{Ni}(\mathrm{OH})_{2}$ should exhibit anti-ferromagnetism due to the mostly double layer structure. However, our experiment result shows that NR$\mathrm{Ni}(\mathrm{OH})_{2}$ exhibits both ferromagnetism and anti-ferromagnetism, which is in stark contrast to the earlier theory. Furthermore, based on the above discussion, this ferromagnetic property should not originate from the nearly negligible amount of uncompensated surface layers. Thus, this unique phenomenon can be attributed to the presence of four-coordinated $\mathrm{Ni}$ atoms, as their electron spins in the $e_{\mathrm{g}}{ }^{*}$ energy band are no longer confined by the interlayer bonding energy. As a result, the electron spin directions in the $e_{\mathrm{g}}{ }^{*}$ orbitals with neighboring $(00 l)$ planes are the same, leading to ferrimagnetic ordering (Fig. 3j). This means that the electrons become delocalized over the four-coordinated $\mathrm{Ni}$ atom. Hence, based on the NEXAFS and DFT simulation results, these delocalized electrons are located at the LHB higher orbital ( $P_{h}$ orbital), which possess higher energy and are near to the Fermi level.
It is well known that the extension of octahedron structure would lead to $e_{\mathrm{g}}{ }^{*}$ level splitting. When this extension reaches infinity, the octahedron structure will transform into square planar with $\left(x^{2}-y^{2}\right)$ orbital energy larger than the Fermi energy level (Fig. 4a). As compared to the traditional six-coordinated $\mathrm{NiO}_{6}$ octahedron, $\mathrm{NR}-\mathrm{Ni}(\mathrm{OH})_{2}$ possesses four-coordinated $\mathrm{Ni}$ atoms with two dangling bonds. Instead of the typical formation of a $\mathrm{NiO}_{4}$ square planar configuration for a four-coordinated $\mathrm{Ni}$ atom, the four-coordinated $\mathrm{Ni}$ atom in $\mathrm{NR}-\mathrm{Ni}(\mathrm{OH})_{2}$ is arranged in $\mathrm{a} \mathrm{NiO}_{6}$ octahedron configuration. Thus, this structure could be perceived as an intermediate configuration between an extended octahedron and square planar as shown in Fig. 4a. As such, the four-coordinated $\mathrm{Ni}$ atoms arrangement is considered to be a special distorted octahedron with delocalized electron states.

After identifying the delocalization of electrons in the fourcoordinated $\mathrm{Ni}$ atom in $\mathrm{NR}-\mathrm{Ni}(\mathrm{OH})_{2}$, the next step is to investigate the effect of these delocalized electrons on the MOR performance. To reveal some insights to the electron transfer mechanism in our four-six-coordinated $\mathrm{NR}-\mathrm{Ni}(\mathrm{OH})_{2}$, an illustration is shown in Fig. 4b. The delocalized electrons in the highest electron occupied orbital $\left(P_{h}\right)$ of the four-coordinated $\mathrm{Ni}$ atom are weakly or not bonded. These delocalized electron orbitals can serve as charge-transfer sites, which transfer electrons from $P_{h}$ to $\left(x^{2}-y^{2}\right)$ and $z^{2}$ orbitals of its neighboring six-coordinated $\mathrm{Ni}$ atom. Eventually, these electrons will then be transferred to the $\left(\mathrm{P}_{h}\right)$ of the next neighboring four-coordinated $\mathrm{Ni}$ atom (Fig. 4b), and such process continues until the electrons enter into the current collector. This proposed electron transfer mechanism agrees well with the isosurface charge density of $\mathrm{NR}-\mathrm{Ni}(\mathrm{OH})_{2} \mathrm{LHB}$ result as shown in Fig. 4c. The isosurface charge distribution indicates the overlapping of the edge $\mathrm{O}$ atoms with the adjacent four $\mathrm{Ni}$ atoms, which could form an effective charge-transfer pathway as the black arrows shows. For square planar structure whose Ni atoms are four-coordinated, the orbitals below Fermi energy level are fully occupied which hinders the transfer of electrons into adjacent orbitals (Fig. 4a). This explains why the four-coordinated $\mathrm{Ni}$ atom must be paired to a neighboring six-coordinated $\mathrm{Ni}$ atom in order to achieve efficient charge transfer.

However, for the traditional $\mathrm{Ni}(\mathrm{OH})_{2}, e_{\mathrm{g}}{ }^{*}$ orbitals in $(\mathrm{M}-\mathrm{O})^{*}$ antibonding bands are occupied by two spin-up electrons which hinders the transfer of electrons into the adjacent $e_{\mathrm{g}}{ }^{*}$ orbital due to the Pauli exclusion principle. When $\mathrm{Ni}(\mathrm{OH})_{2}$ oxidizes into $\mathrm{NiOOH}$, there would only be one spin up electron in the $e_{\mathrm{g}}{ }^{*}$ orbital, which allows effective electron transfer into the adjacent $e_{\mathrm{g}}{ }^{*}$ orbital (Supplementary Fig. 14). This is in good agreement with the reported MOR process of traditional $\mathrm{Ni}(\mathrm{OH})_{2}$, which can be summarized as follows; (a) nickel oxidation of $\mathrm{Ni}^{2+}$ to $\mathrm{Ni}^{3+}$, and (b) methanol oxidation $\mathrm{Ni}^{3+}+\mathrm{CH}_{3} \mathrm{OH} \rightarrow$ $\mathrm{Ni}^{2+}+$ products (spontaneous process) ${ }^{12}$. This indicates that $\mathrm{Ni}$ $(\mathrm{OH})_{2}$ is unable to catalyze methanol oxidation without being oxidized to $\mathrm{NiOOH}$. As the potential for $\mathrm{Ni}$ oxidation is usually larger than $1.35 \mathrm{~V}$ vs. RHE, traditional $\mathrm{Ni}(\mathrm{OH})_{2}$ cannot trigger the operation of DMFCs. This agrees well with our experimental results (Supplementary Table 1). Based on these discussions, we can conclude that achieving efficient charge transfer is the crucial factor in realizing methanol oxidation. We have demonstrated that the electron charge transfer in our periodically arranged four-six-coordinated $\mathrm{Ni}$ atoms in $\mathrm{NR}-\mathrm{Ni}(\mathrm{OH})_{2}$ is indeed efficient, which ultimately contributes toward efficient MOR. It was reported that there was no formation of $\mathrm{NR}-\mathrm{Ni}(\mathrm{OH})_{2}$ with alternating four-six coordinated $\mathrm{Ni}$ atoms when reacting $\mathrm{Ni}(\mathrm{OH})_{2}$ with $\mathrm{S}^{25}$. Combining the results obtained in this work, it is realised that the oxygen content and $\mathrm{Ni}-\mathrm{O}$ bond in $\mathrm{NiS}_{2}$ may exert certain influence on the formation of $\mathrm{NR}-\mathrm{Ni}(\mathrm{OH})_{2}$, which requires further comprehensive studies. 
a

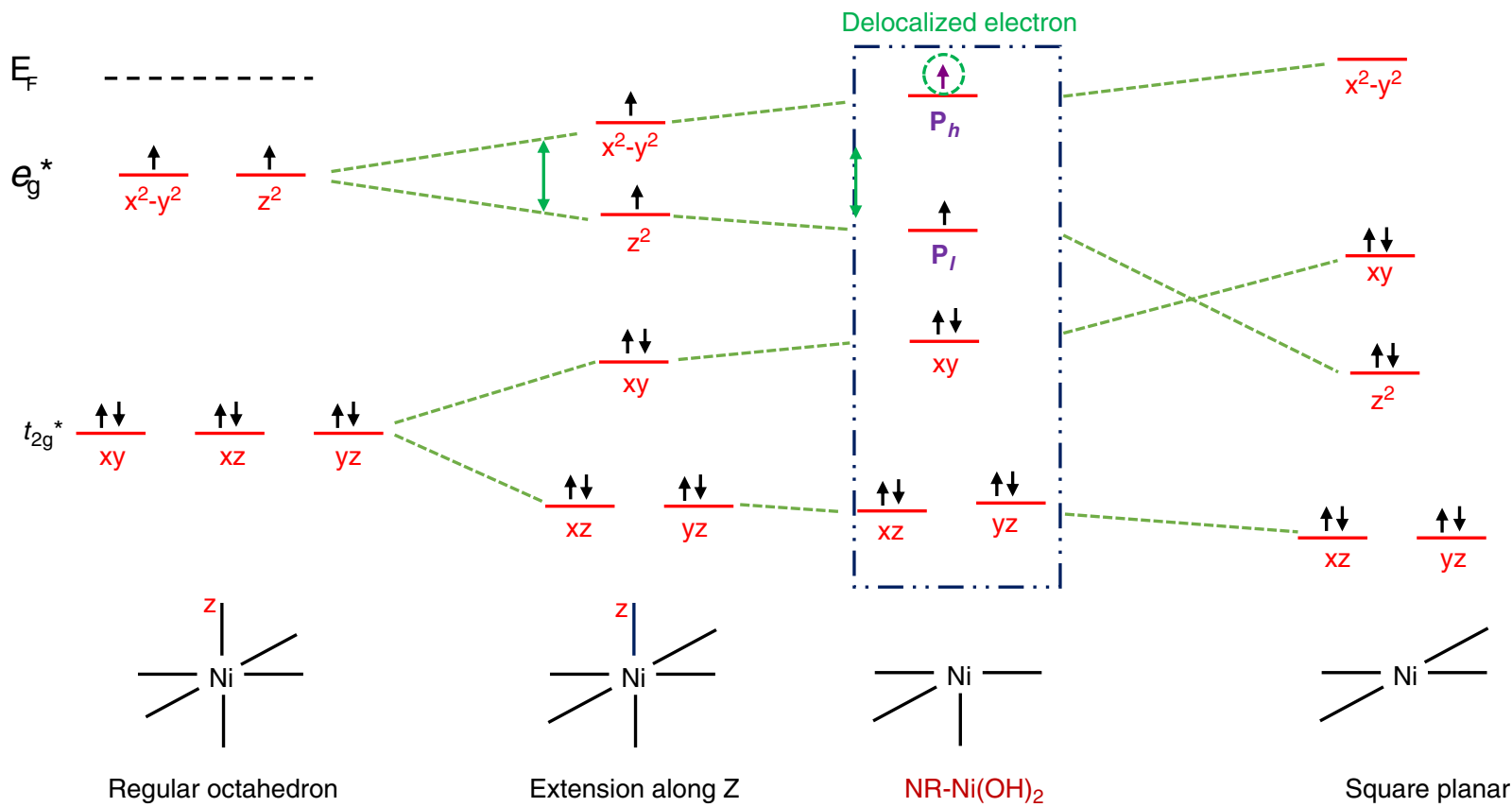

b
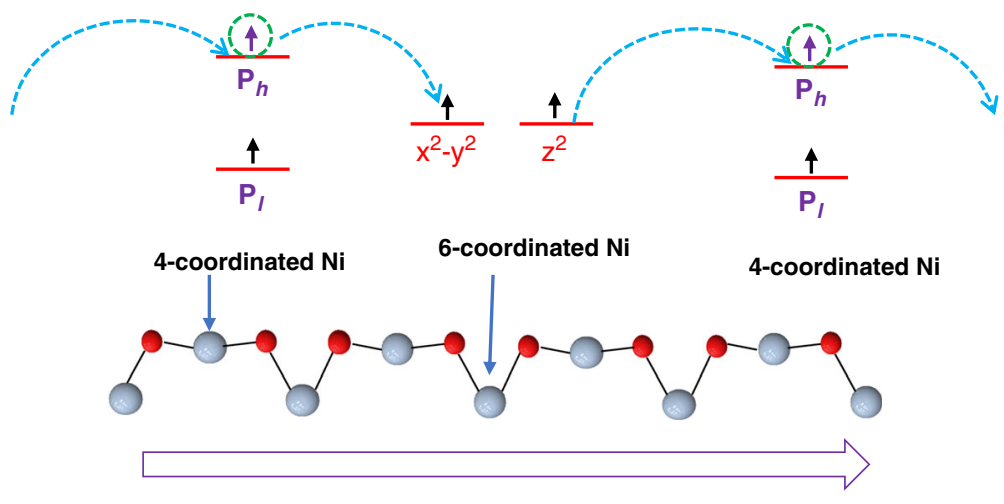

C

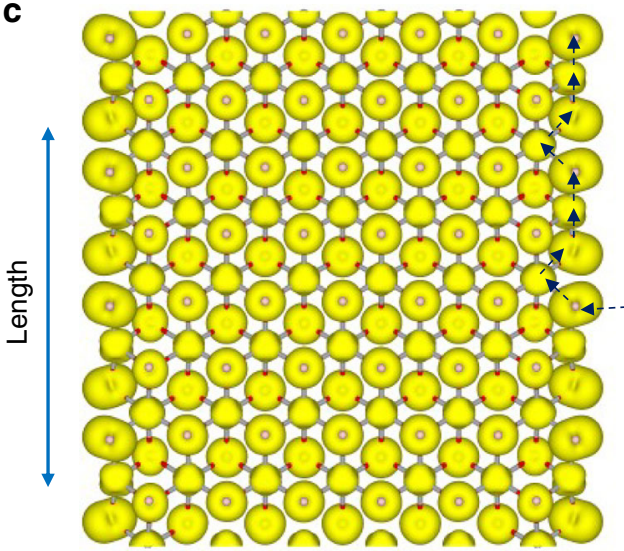

Fig. 4 Schematic of $\mathbf{N R}-\mathbf{N i}(\mathbf{O H})_{\mathbf{2}}$ electronic orbitals and charge transfer pathway. a $t_{2 \mathrm{~g}}{ }^{*}$ and $\mathrm{e}_{\mathrm{g}}{ }^{*}$ electronic orbitals of regular $\mathrm{NiO}_{6}$ octahedron, $\mathrm{NiO}_{6}$ octahedron extended along $z$ axis, $\mathrm{NR}-\mathrm{Ni}(\mathrm{OH})_{2}$, and $\mathrm{NiO}_{4}$ square planar; $\mathbf{b}$ charge transfer process on alternating four-six-coordinated arrangement in $\mathrm{NR}-\mathrm{Ni}(\mathrm{OH})_{2}$; c isosurface of charge density of $\mathrm{NR}-\mathrm{Ni}(\mathrm{OH})_{2} \mathrm{LHB}$.

\section{Discussion}

In summary, our previously reported nickel hydroxide nanoribbon structure (NR-Ni(OH) $)_{2}$ ) is able to show remarkable activity with an onset potential of $0.55 \mathrm{~V}$ vs. RHE. This is mainly due to the generation of available charge-transfer orbitals for electrons delocalized near the Fermi energy level using a four-coordinated $\mathrm{Ni}$ atom, which significantly enhances the six-electron MOR transfer process. Thus, due to our periodically arranged four-sixcoordinated $\mathrm{Ni}$ atoms $\mathrm{NR}-\mathrm{Ni}(\mathrm{OH})_{2}$, methanol conversion to $\mathrm{CO}_{2}$ is highly efficient. Our initial attempt to construct a NR-Ni(OH $)_{2}$ assembled DFMC device shows an operable OCV of $0.58 \mathrm{~V}$, which indicates its feasibility for DMFC operation. Furthermore, the preliminary investigation of the as-assembled DFMC demonstrates durable operation with zero CO poisoning. With these positive demonstrations, it is expected that this strategy will offer a practical gateway toward the development of high performance and durable non-PGM DMFC.

\section{Methods}

Electrode preparation. In brief, the catalyst was ground thoroughly with polyvinylidene fluoride (PVDF) as the binder and carbon black as the conductive medium with a mass ratio: 7:1:2. The solvent used for the grinding process was $\mathrm{N}$-methy-2-pyrrolidone (NMP) solution. Eventually, a uniform slurry was obtained. The uniform slurry was then pasted onto the carbon paper $(0.18 \mathrm{~mm}$, with $77 \%$ porosity). The carbon paper with coated slurry was heated in a conventional oven overnight at $80^{\circ} \mathrm{C}$.

\section{Characterization}

Near-edge X-ray absorption fine structure. Near-edge X-ray absorption fine structure (NEXAFS) spectra were measured at Singapore Synchrotron Light Sources (SSLS). The Ni $L_{2}, L_{3}$ and O K edge NEXAFS spectra was collected in total electron yield mode with a photon energy resolution of $350 \mathrm{meV}$. The photon energy was calibrated using the characteristic intensity dip at $284.4 \mathrm{eV}$ from the contamination carbon of the beamline optical components. All NEXAFS spectra are normalized to the incident photon intensity $\left(I_{0}\right)$ monitored by the focusing mirror.

Fourier transform infrared spectra. Fourier transform infrared (FTIR) spectra were collected with a PerkinElmer Frontier MIR/FIR system by 16 scans with a nominal resolution of $1 \mathrm{~cm}^{-1}$

Electrochemical measurement. Electrochemical measurements were performed using a three-electrode system connected to an electrochemical workstation (VMP3, Bio-logic Inc) with built-in electrochemical impedance spectroscopy (EIS) analyzer. The reference electrode is a $\mathrm{Hg} / \mathrm{HgO}$ electrode, which was calibrated through the method below. 
Magnetic measurement. The magnetic properties were investigated using a superconducting quantum interface device (SQUID) magnetometer.

\section{Direct methanol fuel cell assembly and performance evaluation}

Ion conductor solution preparation. $0.25 \mathrm{~g}$ of Fumasep FAA-3-PK-130 alkaline membrane was firstly cut into small pieces. Then, the small membrane pieces were dissolved in $5 \mathrm{ml} \mathrm{N}$-methy-2-pyrrolidone (NMP) solution through heating at $150{ }^{\circ} \mathrm{C}$ for $3 \mathrm{~h}$, to give a brown ion conductor solution.

Membrane electrode assembly (MEA) preparation. The catalyst solution was prepared by mixing $40 \%$ catalyst, $40 \%$ carbon black, $30 \%$ ion conductor solution. Then, the ink was coated on gas diffusion layer at $60^{\circ} \mathrm{C}$. Next, the MEA was prepared by pressing the anode, membrane and cathode electrode under $1.4 \mathrm{MPa}$ at $80^{\circ} \mathrm{C}$ for $3 \mathrm{~min}$, with the size of $5 \mathrm{~cm}^{2}$.

DMFC performance evaluation. DMFC devices was assemble as shown in Fig. S4, and the performance was evaluated using a fuel cell test system (850e, Scribner) at $80^{\circ} \mathrm{C}$, with a $1 \mathrm{M}$ methanol concentration and $\mathrm{O}_{2}$ flow rate of $190 \mathrm{cc} / \mathrm{min}$. The active cell area of DMFC was $5 \mathrm{~cm}^{2}$

\section{Computational method}

$\mathrm{NR}-\mathrm{Ni}(\mathrm{OH})_{2}$ construction. All calculations were carried out using the density functional theory (DFT) with the generalized Perdew-Burke-Ernzerhof (PBE) and DFT + $U\left(U_{\text {eff }}=U-J=5.3\right)$, and the projector augmented-wave (PAW) pseudopotential planewave method as implemented in the VASP code. For the PAW pseudopotential, we included $3 d^{8} 4 s^{2}, 2 s^{2} 2 p^{4}$ and $1 s^{1}$ were treated as valence electrons for $\mathrm{Ni}, \mathrm{O}$, and $\mathrm{H}$ atoms, respectively. A $12 \times 12 \times 10$ Monkhorst-Pack (MP) k-point grid was used for $\mathrm{Ni}(\mathrm{OH})_{2}$ unitcell geometry optimization calculations. Good convergence was obtained with these parameters, and the total energy was converged to $1 \times 10^{-6} \mathrm{eV}$ per atom. Energy convergence with respect to the plane wave cutoff was tested by varying this setting between 300 and $600 \mathrm{eV}$ considering the electron spinpolarization. Convergence to within $10 \mathrm{meV}$ was achieved with a cutoff energy of $500 \mathrm{eV}$ for $\mathrm{Ni}$ $(\mathrm{OH})_{2}$ unitcell. We carried out calculations with the van der Waals (vdW) correction by employing optPBE-vdW functional, and the reaction paths of sequential hydrogen abstraction steps are calculated by means of the Nudged Elastic Band (NEB) method. Nickel hydroxide has two different crystalline forms, named $\alpha$ - and $\beta-\mathrm{Ni}(\mathrm{OH})_{2}$, and latter is the most stable form of nickel hydroxide with the point group of $P \overline{3} m 1$ (No. 164). $\beta-\mathrm{Ni}(\mathrm{OH})_{2}$ has a layered structure, with $\mathrm{OH}^{-}$anions between nickel ions, and layers stack together by hydrogen bonds. In our calculations, we optimized the unitcell of $\mathrm{Ni}(\mathrm{OH})_{2}$ and the calculated lattice constants are, $\mathrm{a}=\mathrm{b}=3.04$ and $\mathrm{c}=4.61 \AA$. Compared with the experimental values of $\mathrm{a}=\mathrm{b}=3.12 \AA$ and $\mathrm{c}=4.66 \AA^{26}$, we consider that our basic settings are correct and our calculation results are reliable. Based the optimized layered unitcell of $\mathrm{Ni}(\mathrm{OH})_{2}$ and the experimental results, we constructed $\mathrm{Ni}(\mathrm{OH})_{2}$ nanoribbons (NRs) supercell for methanol decomposition study (Supplementary Fig. 6). It should be noted that all energies reported here are corrected with the zero-point energy (ZPE).

Calculations of MOR activity. We carried out calculations with the van der Waals (vdW) correction by employing the optPBE-vdW functional, and the reaction paths of sequential hydrogen abstraction steps are calculated by means of the NEB method. It should be noted that all energies reported here are corrected with the ZPE.

\section{Data availability}

The authors declare that all data supporting the finding of this study are available within the paper and its Supplementary information files.

Received: 7 April 2020; Accepted: 12 August 2020;

Published online: 16 September 2020

\section{References}

1. MÜller, M., Kimiaie, N., GlÜsen, A. \& Stolten, D. The long way of achieving a durability of 20,000 h in a DMFC system. Adv. Sci. Technol. 93, 56-60 (2014).

2. Zhao, X. et al. Recent advances in catalysts for direct methanol fuel cells. Energy Environ. Sci. 4, 2736 (2011).

3. Gottesfeld, S. in Handbook of fuel cells-fundamentals, technology and applications (John Wiley \& Sons, Caesarea, 2010).

4. Kang, K., Park, S., Choi, K. \& Ju, H. Development of lightweight 200-W direct methanol fuel cell system for unmanned aerial vehicle applications and flight demonstration. Fuel cells 14, 594-700 (2014).

5. Sgroi, M. et al. Cost analysis of direct methanol fuel cell stacks for mass production. Energies 9, 1008 (2016).

6. Huang, H. J. \& Wang, X. Recent progress on carbon-based support materials for electrocatalysts of direct methanol fuel cells. J. Mater. Chem. A 2, 6266 (2014).
7. Francke, R., Schille, B. \& Roemelt, M. Homogeneously catalyzed electroreduction of carbon dioxide-methods, mechanisms, and catalysts. Chem. Rev. 118, 4631-4701 (2018).

8. Liu, H. et al. A review of anode catalysis in the direct methanol fuel cell. $J$. Power Sources 155, 95-110 (2006).

9. Cui, X. et al. $\mathrm{SnO}_{2}$ nanocrystal-decorated mesoporous ZSM-5 as a precious metal-free electrode catalyst for methanol oxidation. Energy Environ. Sci. 8, 1261 (2015).

10. Yue, X. et al. Fluorine-doped and partially oxidized tantalum carbides as nonprecious metal electrocatalysts for methanol oxidation reaction in acidic media. Adv. Mater. 28, 2163-2169 (2016).

11. Serov, A. \& Kwak, C. Review of non-platinum anode catalysts for DMFC and PEMFC application. Appl. Catal. B 90, 313-320 (2009).

12. Wu, D., Zhang, W. \& Cheng, D. Facile synthesis of $\mathrm{Cu} / \mathrm{NiCu}$ electrocatalysts integrating alloy, core-shell, and one-dimensional structures for efficient methanol oxidation reaction. ACS Appl. Mater. Inter. 9, 19843-19851 (2017).

13. Huang, W. et al. Highly active and durable methanol oxidation electrocatalyst based on the synergy of platinum-nickel hydroxide-graphene. Nat. Commun. 6, 10035 (2015).

14. Feng, Y., Liu, H. \& Yang, J. A selective electrocatalyst-based direct methanol fuel cell operated at high concentrations of methanol. Sci. Adv. 3, e1700580 (2017).

15. Wang, X. P. et al. Strained stabilized nickel hydroxide nanoribbons for efficient water splitting. Energy Environ. Sci. 13, 229-237 (2020).

16. Ziv, N. \& Dekel, D. R. A practical method for measuring the true hydroxide conductivity of anion exchange membranes. Electrochem. commun. 88, 109-113 (2018).

17. Rodriguez, P., Kwon, Y. \& Koper, M. T. M. The promoting effect of adsorbed carbon monoxide on the oxidation of alcohols on a gold catalyst. Nat. Chem. 4, 177 (2012).

18. Bianchi, D., Chafik, T., Khalfallah, M. \& Teichner, S. J. Intermediate species on zirconia supported methanol aerogel catalysts V. adsorption of methanol. Appl. Catal. A, Gen. 123, 89-110 (1995).

19. Daturi, M., Binet, C., Lavalley, J., Galtayries, A. \& Sporken, R. Surface investigation on $\mathrm{Ce}_{x} \mathrm{Zr}_{1-x} \mathrm{O}_{2}$ compounds. Phys. Chem. Chem. Phys. 1, 5717-5724 (1999)

20. Chen, Y. X., Miki, A., Ye, S., Sakai, H. \& Osawa, M. Formate, an active intermediate for direct oxidation of methanol on Pt electrode. J. Am. Chem. Soc. 125, 3680-3681 (2003).

21. Huang, Z. F. et al. Chemical and structural origin of lattice oxygen oxidation in Co-Zn oxyhydroxide oxygen evolution electrocatalysts. Nat. Energy 4, 329-338 (2019).

22. Li, N. et al. Influence of iron doping on tetravalent nickel content in catalytic oxygen evolving films. Proc. Natl Acad Sci. USA 114, 1486-1491 (2017).

23. Kleiner, $\mathrm{K}$. et al. Unraveling the degradation process of $\mathrm{LiNi}_{0.8} \mathrm{Co}_{0.15} \mathrm{Al}_{0.05} \mathrm{O}_{2}$ electrodes in commercial lithium ion batteries by electronic structure investigations. ACS Appl. Mater. Inter. 7, 19589-19600 (2015).

24. Rall, J. D. \& Seehra, M. S. Metamagnetism and nanosize effects in the magnetic properties of the quasi-two-dimensional system $\beta-\mathrm{Ni}(\mathrm{OH})_{2}$. Phys. Rev. B. 82, 184403 (2010)

25. Ding, X. et al. An Fe stabilized metallic phase of NiS2 for highly efficient oxygen evolution reaction. Nanoscale 11, 23217 (2019).

26. Kazimirov, V. Y. et al. Atomic structure and lattice dynamics of $\mathrm{Ni}$ and $\mathrm{Mg}$ hydroxides. Solid State Ion. 181, 1764-1770 (2010).

\section{Acknowledgements}

This work is financially supported by Singapore MOE Tier 1 R284000226114 and MOE Tier 2 (MOE2018-T2-1-149), Technology and Research (A*STAR) of Singapore. This research is also supported by A*STAR with a Grant No. of 152-70-00017 and computational resources were provided by National Supercomputing Centre Singapore (NSCC) and $A^{*}$ STAR Computational Resource Centre, Singapore (A*CRC). This project was partly supported by the Science and Engineering Research Council (SERC) of A*STAR of Singapore. S. J. Pennycook is grateful to the National University of Singapore and a MOE Tier 2 (MOE2017-T2-1-129) project for support. W.C. Hao is grateful to the National Science Foundation of China (No. 11874003 and No.51672018). X.P. Wang is grateful to graphic designer Hui Wang for her help in figure design.

\section{Author contributions}

X.P.W., S.B.X., and J.M.X. conceived the idea. X.P.W. performed synthesis and electrochemical measurement of the samples. W.S.V.L., H.J.W., H.W., and S.J.P. were responsible for the analysis of STEM and FTIR results. P.C., L.Z., X.S.Z., and Z.B.W. were in charge of DMFC test. S.B.X., A.B., C.Z.D., and Y.H.D. were responsible for the NEXAS characterization. Z.G.Y., and P.R.H. carried out DFT simulations. W.C.H. conducted magnetic measurement. J.M.X. is in charge of the overall project and preparation of the paper.

\section{Competing interests}

The authors declare no competing interests. 


\section{Additional information}

Supplementary information is available for this paper at https://doi.org/10.1038/s41467020-18459-9.

Correspondence and requests for materials should be addressed to Y.D., Z.G.Y., S.P. or J.X.

Peer review information Nature Communications thanks Jeong Gil Seo, Andreas Glüsen and the other, anonymous, reviewer(s) for their contribution to the peer review of this work. Peer reviewer reports are available.

Reprints and permission information is available at http://www.nature.com/reprints

Publisher's note Springer Nature remains neutral with regard to jurisdictional claims in published maps and institutional affiliations. (c) (i) Open Access This article is licensed under a Creative Commons Attribution 4.0 International License, which permits use, sharing, adaptation, distribution and reproduction in any medium or format, as long as you give appropriate credit to the original author(s) and the source, provide a link to the Creative Commons license, and indicate if changes were made. The images or other third party material in this article are included in the article's Creative Commons license, unles indicated otherwise in a credit line to the material. If material is not included in the article's Creative Commons license and your intended use is not permitted by statutory regulation or exceeds the permitted use, you will need to obtain permission directly from the copyright holder. To view a copy of this license, visit http://creativecommons.org/ licenses/by/4.0/.

(C) The Author(s) 2020 